\title{
Inhibitory effects of Pericarpium zanthoxyli extract on adipocyte differentiation
}

\author{
HA-RIM KIM $^{1 *}$, JEONG-MI KIM ${ }^{1 *}$, MI-SEONG KIM ${ }^{1}$, JIN-KI HWANG $^{1}$, SEI-HOON YANG ${ }^{2}$, \\ HYE-JUNG KIM ${ }^{3}$, DONG-SUNG LEE ${ }^{4}$, HYUNCHEOL OH ${ }^{4-6}$, YOUN-CHUL KIM ${ }^{4-6}$, \\ DO-GON RYU ${ }^{7}$, YOUNG-RAE LEE ${ }^{1,8,9}$ and KANG-BEOM KWON ${ }^{1,7,9}$
}

\begin{abstract}
${ }^{1}$ Center for Metabolic Function Regulation, ${ }^{2}$ Department of Internal Medicine, Wonkwang University School of Medicine, Iksan, Jeonbuk 570-749; ${ }^{3}$ Department of Family Medicine, The Catholic University of Korea, Incheon St. Mary's Hospital, Bupyeong-gu, Incheon 403-720; ${ }^{4}$ Hanbang Body-Fluid Research Center, ${ }^{5}$ Standardized Material Bank for New Botanical Drugs, College of Pharmacy, ${ }^{6}$ Institute of Pharmaceutical Research and Development, College of Pharmacy, Wonkwang University; ${ }^{7}$ Department of Korean Physiology, Wonkwang University School of Korean Medicine;

${ }^{8}$ Department of Oral Biochemistry and Institute of Biomaterials - Implant, School of Dentistry,

${ }^{9}$ BK21 Plus Program and Department of Smart Life-Care Convergence, Graduate School,

Wonkwang University, Iksan, Jeonbuk 570-749, Republic of Korea
\end{abstract}

Received December 2, 2013; Accepted February 20, 2014

DOI: $10.3892 / \mathrm{ijmm} .2014 .1667$

\begin{abstract}
Obesity is a risk factor associated with numerous disorders, such as type 2 diabetes, hypertension, dyslipidemia and coronary heart disease. In this study, we investigated the inhibitory effects of Pericarpium zanthoxyli extract (PZE) on the adipocytic differentiation of OP9 cells. During adipocyte differentiation, the OP9 cells were treated with 0,10 and $20 \mu \mathrm{g} /$ $\mathrm{ml}$ of PZE at various time intervals, followed by the examination of lipid droplet formation and the mRNA expression of adipogenesis-related genes. The cells treated with PZE during the early period (days 0-2) showed a significant reduction in the accumulation of lipid droplets, which were induced by a standard adipogenic cocktail, as well as a decrease in the expression of the adipogenesis-related transcription factor, peroxisome proliferator-activated receptor $\gamma$ (PPAR $\gamma)$ and PPAR $\gamma$-target genes, such as adipocyte protein 2 (aP2), fatty acid synthase (FAS) and other adipocyte markers. Adipocyte differentiation
\end{abstract}

Correspondence to: Professor Young-Rae Lee, Department of Oral Biochemistry and Institute of Biomaterials - Implant, School of Dentistry, Wonkwang University, 460 Iksan-daero, Iksan, Jeonbuk 570-749, Republic of Korea

E-mail:mindyr@wku.ac.kr

Professor Kang-Beom Kwon, Department of Korean Physiology, Wonkwang University School of Korean Medicine, 460 Iksan-daero, Iksan, Jeonbuk 570-749, Republic of Korea

E-mail: desson@wku.ac.kr

${ }^{*}$ Contributed equally

Key words: Pericarpium zanthoxyli extract, differentiation, adipocyte, peroxisome proliferator-activated receptor $\gamma$, CCAAT/enhancer-binding protein $\beta$ was not inhibited by treatment with PZE during the late stage of differentiation (days 3-5). Thus, the inhibitory effects of PZE on adipocyte differentiation occurred during the early stages of adipogenesis, which was confirmed by the decrease in the levels of CCAAT/enhancer-binding protein $\beta(\mathrm{C} / \mathrm{EBP} \beta)$ in a dose-dependent manner when the OP9 cells were exposed to PZE. Taken together, our results indicate that PZE inhibit the early stages of adipogenic differentiation by inhibiting $\mathrm{C} / \mathrm{EBP} \beta$ expression.

\section{Introduction}

Pericarpium zanthoxyli (PZ) is the dried pericarp of the ripe fruit of Zanthoxylum schinifolium (Sieb. and Zucc) or Zanthoxylum bungeanum (Maxim.), of the Rutaceae family. Although it has been used to alleviate pain and increase appetite in Asian medicine, the effects of PZ on adipocyte differentiation and the underlying mechanisms have not been elucidated.

Obesity is a worldwide epidemic, and there are multiple obesity-associated health issues, including type 2 diabetes, hypertension and cardiovascular disease (1). Obesity is caused by adipocyte hyperplasia, as well as hypertrophy. Adipocyte hypertrophy induces the transformation of preadipocytes into adipocytes $(2,3)$, with preadipocytes initiating the expression of differentiation-related transcription factors when the cells are exposed to adipogenic inducers $(4,5)$. Adipocyte differentiation also requires a concerted cellular program, including the growth arrest of confluent preadipocytes [termed mitotic clonal expansion (MCE)] and the initiation of transcriptional events during the early and late stages of differentiation (4). CCAAT/enhancer-binding protein $(\mathrm{C} / \mathrm{EBP}) \beta$ and $\mathrm{C} / \mathrm{EBP} \delta$ are the first transcription factors to be expressed during adipocyte differentiation. The increased activities of $\mathrm{C} / \mathrm{EBP} \beta$ and $\mathrm{C} / \mathrm{EBP} \delta$ are thought to mediate the expression of peroxisome 
proliferator-activated receptor $\gamma(\operatorname{PPAR} \gamma)$ and $\mathrm{C} / \mathrm{EBP} \alpha$ during adipogenesis $(5,6)$.

To investigate the mechanisms responsible for adipocyte differentiation, glucose uptake by insulin and lipid metabolism, the 3T3-L1 cell culture model has normally been used. However, 3T3-L1 cells have significant limitations, including a long interval between preadipocyte formation and adipocyte maturation (7), and a limited passage for differentiation. To overcome these limitations, we used OP9 mouse stromal cells in this study, as first reported in the study by Wolins et al (8) as a useful new model of adipocyte differentiation. In their study, OP9 cells differentiated into adipocytes after being confluent and subsequent to many passages and long periods in culture, unlike 3T3-L1 cells. Furthermore, the OP9 cells initiated the same events, including lipid metabolism, insulin signaling and glucose transport, very similar to 3T3-L1 cells (8).

In the present study, the effects of PZ extract (PZE) on the adipocytic differentiation of OP9 cells were investigated by measuring lipid accumulation and evaluating the expression levels of adipocyte marker genes and their target genes. We also examined its mechanisms of action in adipocyte differentiation by treating the cells with PZE during the early (days 0-2) and late stages of differentiation (days 3-5) .

\section{Materials and methods}

Reagents. The OP9 cells were purchased from the American Type Culture Collection (ATCC; Manassas, VA, USA). Minimum essential medium $\alpha(\mathrm{MEM} \alpha)$, fetal bovine serum (FBS), Alexa Fluor ${ }^{\circledR} 568$ goat anti-rabbit IgG and BODIPY $^{\circledR}$ 493/503 dye were purchased from Invitrogen (Carlsbad, CA, USA). Insulin, 3-isobutyl-1-methylxanthine (IBMX), dexamethasone (DEXA) and Oil Red O dye were purchased from Sigma Chemical Co. (St. Louis, MO, USA). Antibodies against PPAR $\gamma, \mathrm{C} / \mathrm{EBP} \alpha, \mathrm{C} / \mathrm{EBP} \beta$ and $\beta$-actin were purchased from Santa Cruz Biotechnology, Inc. (Santa Cruz, CA, USA). Antibodies against extracellular signal-regulated kinases 1/2 (ERK1/2), phospho-ERK1/2, protein kinase B (Akt) and phospho-Akt were obtained from Cell Signaling Technology (Beverly, MA, USA). All the chemicals used were of analytical grade.

Preparation of PZE. The pericarp of Zanthoxylum piperitum D.C. (Rutaceae) were purchased in May 2010 from the Wonkwang University Oriental Herbal Drugstore, Iksan, Korea, and were identified by Professor Youn-Chul Kim, College of Pharmacy, Wonkwang University. A voucher specimen (no. WP10-05-1) was deposited at the Herbarium of the College of Pharmacy, Wonkwang University. The dried and pulverized pericarps of Zanthoxylum piperitum $(50 \mathrm{~g})$ were extracted twice with hot $70 \%$ ethanol (1 liter) for $2 \mathrm{~h}$ at room temperature and filtered with filter paper. The filtrate was evaporated in vacuo to produce a $70 \%$ ethanol extract $(10.64 \mathrm{~g}, 21.3 \mathrm{w} / \mathrm{w} \%)$. The $70 \%$ ethanol extract was suspended in distilled water $(100 \mathrm{ml})$, followed by filtration. The residue derived from the filtration was dissolved in hot ethanol and filtered again. The filtrate was then evaporated in vacuo to obtain a standardized fraction of Zanthoxylum piperitum (NNMBS142, $3.29 \mathrm{~g}, 6.58 \mathrm{w} / \mathrm{w} \%$ ). NNMBS142 was deposited at the Standardized Material Bank for New Botanical Drugs, Wonkwang University. Radix astragali extracts were also received from Professor Youn-Chul Kim and used as a negative control. The extraction methods for Radix astragali were the same as those used for PZE.

Cell culture and induction of adipocyte differentiation. The OP9 cells were cultured in MEM $\alpha$ containing 20\% FBS, 2 mM L-glutamine, $100 \mathrm{U} / \mathrm{ml}$ penicillin and $100 \mu \mathrm{g} / \mathrm{ml}$ streptomycin at $37^{\circ} \mathrm{C}$ in a $5 \% \mathrm{CO}_{2}$ incubator. To induce differentiation, 1-day post-confluent preadipocytes were incubated in differentiation medium containing 10\% FBS, $0.5 \mathrm{mM}$ IBMX, $0.25 \mu \mathrm{M}$ DEXA, $175 \mathrm{nM}$ insulin, $2 \mathrm{mM}$ L-glutamine, $100 \mathrm{U} / \mathrm{ml}$ penicillin and $100 \mu \mathrm{g} / \mathrm{ml}$ streptomycin for 2 days. The medium was then changed to MEM $\alpha$ containing $10 \%$ FBS, 2 mM L-glutamine, and $175 \mathrm{nM}$ insulin, and the cells were cultured for 3 days. Control cells [no differentiation (ND)] were cultured in MEM $\alpha$ containing 10\% FBS, 2 mM L-glutamine, $100 \mathrm{U} / \mathrm{ml}$ penicillin, and $100 \mu \mathrm{g} / \mathrm{ml}$ streptomycin without IBMX, DEXA and insulin for 5 days.

Determination of cell viability. The effects of PZE on OP9 cell viability were determined using an established MTT assay. Briefly, the cells were seeded in a 96-well dish and incubated at $37^{\circ} \mathrm{C}$ for $24 \mathrm{~h}$ to allow attachment. The attached cells were either untreated [control (CON)] or treated with 10 or $20 \mu \mathrm{g} / \mathrm{ml} \mathrm{PZE}$ for various periods of time at $37^{\circ} \mathrm{C}$. The cells were washed with phosphate-buffered saline (PBS) prior to the addition of MTT $(0.5 \mathrm{mg} / \mathrm{ml} \mathrm{PBS})$ and incubated at $37^{\circ} \mathrm{C}$ for $30 \mathrm{~min}$. Formazan crystals were dissolved with dimethyl sulfoxide (100 $\mu \mathrm{l} /$ well $)$ and detected at $\mathrm{OD}_{570}$ with a model Emax (Molecular Devices, Sunnyvale, CA, USA).

Oil Red $O$ staining. After the induction of adipocyte differentiation, the cells were washed with cold PBS, fixed at room temperature with $4 \%$ formalin for $1 \mathrm{~h}$, and then rinsed with $60 \%$ isopropanol. The OP9 cells were stained with Oil Red O for $1 \mathrm{~h}$ at room temperature and washed 4 times with distilled water. The retained Oil Red $\mathrm{O}$ dye in the cells was quantified by elution into isopropanol, and the $\mathrm{OD}_{500}$ was measured.

Automated image acquisition and processing. Following adipocyte differentiation, the cells were washed with a cold PBS, fixed at room temperature with $4 \%$ paraformaldehyde for 30 min, washed 3 times with cold PBS, and then added to a blocking buffer and incubated for $45 \mathrm{~min}$ at room temperature to prevent non-specific antibody binding. PPAR $\gamma$ or $\mathrm{C} / \mathrm{EBP} \beta$ antibodies were then added to the cells following by overnight incubation; the cells were then washed, and washed again 3 times, and incubated with BODIPY 493/503 dye for lipid droplets, DAPI for the nucleus and Alexa Fluor 568 goat antirabbit or anti-mouse IgG for PPAR $\gamma$ and $\mathrm{C} / \mathrm{EBP} \beta$, respectively, for $1 \mathrm{~h}$. Images were acquired on an ArrayScan ${ }^{\mathrm{TM}}$ VTi automated microscopy and image analysis system (Cellomics Inc., Pittsburgh, PA, USA). Using the system of an automated highly sensitive fluorescence imaging microscope with a x20 objective and suitable filter sets, the stained cells were identified with DAPI in fluorescence channel 1, BODIPY 493/503 in channel 2 and Alexa Fluor 568 in channel 3. The arbitrary value for BODIPY, C/EBP $\beta$ and PPAR $\gamma$ calculated from the standard deviation of the intensity of the pixels under the channel measuring DAPI reflected the content of the intact DNA. 
Table I. Primers and probes for real-time quantitative PCR.

\begin{tabular}{llr}
\hline Genes & \multicolumn{1}{c}{ Primer sequences } & Accession no. \\
\hline PPAR $\gamma$ & 5'-GAAAGACAACGGACAAATCACC-3' & NM_011146 \\
C/EBP $\alpha$ & 5'-GGGGGTGATATGTTTGAACTTG-3' & NM_007678 \\
& 5'-TTGTTTGGCTTTATCTCGGC-3' & N' \\
FABP4 & 5'-CCAAGAAGTCGGTGGACAAG-3' 024406 \\
FAS & 5'-AGCCTTTCTCACCTGGAAGA-3' \\
& 5'-TTGTGGCAAAGCCCACTC-3' \\
HSL & 5'-TGATGTGGAACACAGCAAGG-3' \\
& 5'-GGCTGTGGTGACTCTTAGTGATAA-3' & NM_007988 \\
LPL & 5'-GGAGCACTACAAACGCAACGA-3' & NM_010719 \\
GAPDH & 5'-TCGGCCACCGGTAAAGAG-3' & NM_008509 \\
& 5'-GGACGGTAACGGGAATGTATGA-3' & N'-TGACATTGGAGTCAGGTTCTCTCT-3' \\
\hline
\end{tabular}

PCR, polymerase chain reaction; PPAR $\gamma$, peroxisome proliferator-activated receptor $\gamma$; C/EBP $\alpha$, CCAAT/enhancer-binding protein $\alpha$; FAS, fatty acid synthase; HSL, hormone-sensitive lipase; LPL, lipoprotein lipase; GAPDH, glyceraldehyde 3-phosphate dehydrogenase.

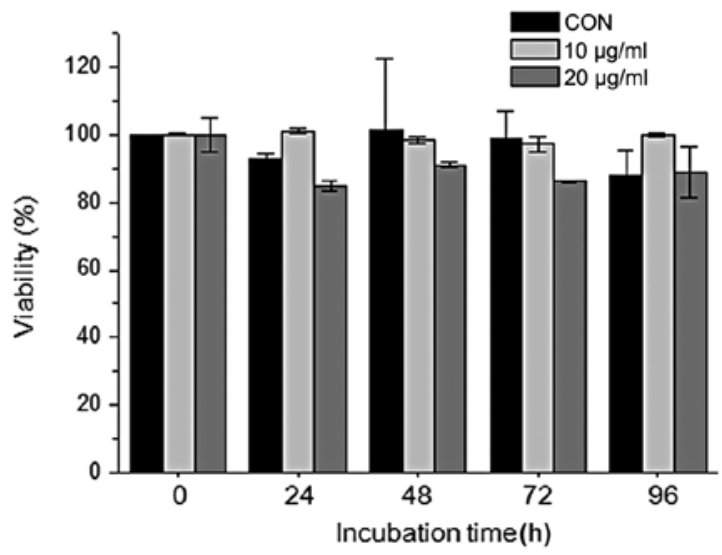

Figure 1. Effects of Pericarpium zanthoxyli extract (PZE) on the viability of OP9 cells. Confluent OP9 cells were allowed to differentiate into adipocytes in differentiation medium for different periods of time and treated with PZE at the concentration of 10 and $20 \mu \mathrm{g} / \mathrm{ml}$. The effects of PZE on cell viability were measured by MTT assay. The data are presented as relative cell viability values. Data are the means \pm standard deviation (SD) values of at least 3 independent experiments. CON, control (untreated cells).

Quantitative reverse transcription-polymerase chain reaction ( $q R T-P C R)$. Total RNA was extracted from the cells using a FastPure ${ }^{\mathrm{TM}}$ RNA kit (Takara, Shiga, Japan). The RNA concentration and purity were determined by absorbance at $260 / 280 \mathrm{~nm}$. cDNA was synthesized from $1 \mu \mathrm{g}$ of total RNA using a PrimeScript ${ }^{\mathrm{TM}}$ RT reagent kit (Takara). Adipocyte differentiation-related gene mRNA expressions were determined by real-time (quantitative) PCR using the ABI PRISM ${ }^{\circledR} 7900$ Sequence Detection System and SYBR ${ }^{\circledR}$-Green I (Applied Biosystems, Foster City, CA, USA). The primer sequences are listed in Table I. All the results were normalized to the housekeeping gene, glyceraldehyde 3-phosphate dehydrogenase (GAPDH), to control for variation in mRNA concentrations.
Relative quantification was performed using the comparative $\Delta \Delta \mathrm{C}_{\mathrm{t}}$ method according to the manufacturer's instructions (Applied Biosystems).

Western blot analysis. The OP9 cells were pre-treated with $20 \mu \mathrm{g} / \mathrm{ml}$ PZE for $1 \mathrm{~h}$ and then differentiation was induced at $37^{\circ} \mathrm{C}$. The cells were lysed with ice-cold M-PER ${ }^{\circledR}$ Mammalian Protein Extraction Reagent (Pierce Biotechnology, Rockford, IL, USA), and the protein concentration in the lysate was determined using the Bradford method (9). Samples $(20 \mu \mathrm{g})$ were separated by sodium dodecyl sulfate-polyacrylamide gel electrophoresis with $10 \%$ acrylamide, and transferred onto Hybond ${ }^{\mathrm{TM}}-\mathrm{P}$ polyvinylidene fluoride membranes (GE Healthcare Life Sciences, Buckinghamshire, UK) using a western blot apparatus. Each membrane was blocked for $2 \mathrm{~h}$ with $2 \%$ bovine serum albumin or $5 \%$ skim milk and then incubated overnight at $4^{\circ} \mathrm{C}$ with $1 \mu \mathrm{g} / \mathrm{ml}$ of a 1:2,000 dilution of the primary antibody. HRP-conjugated $\operatorname{IgG}(1: 2,000$ dilution) was used as the secondary antibody. Protein expression levels were determined by signal analysis using an image analyzer (Fuji-Film, Tokyo, Japan).

Statistical analysis. Statistical analysis was performed using analysis of variance and Duncan's test. Differences with P-values $<0.05$ were considered statistically significant.

\section{Results}

PZE inhibits adipocyte differentiation. In our experiments, we investigated whether PZE inhibits the differentiation of OP9 preadipocytes into mature adipocytes. To understand the molecular basis underlying PZE-inhibited adipogenesis, we first attempted to clarify the key stage during adipocyte differentiation that are critical to the anti-adipogenic effects of PZE, and 

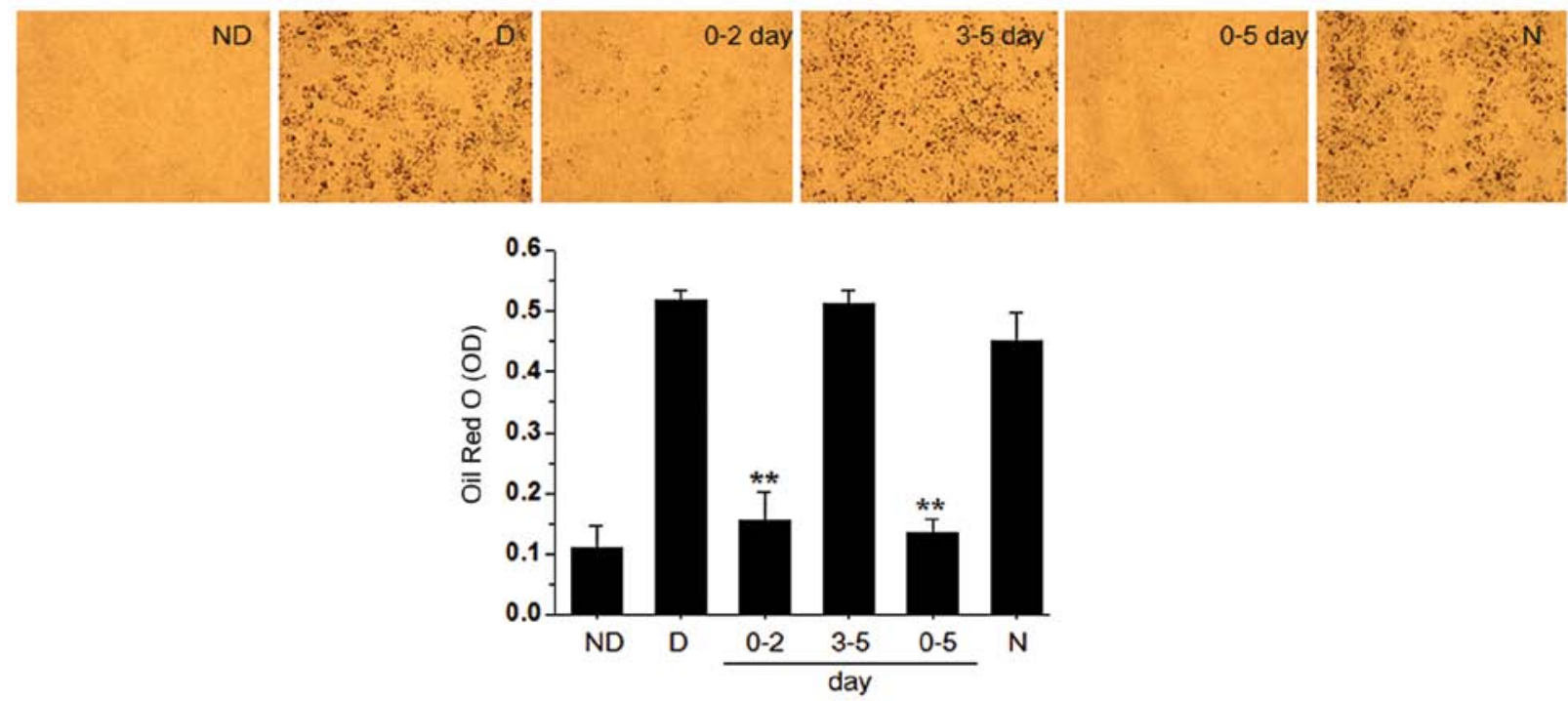

Figure 2. Effects of Pericarpium zanthoxyli extract (PZE) on lipid accumulation of OP9 cells. OP9 cells were induced with multiple daily insulin (MDI) to trigger differentiation into adipocytes. Subseuqently, $20 \mu \mathrm{g} / \mathrm{ml}$ PZE were added at the early (0-2 days) and late stages of differentiation (3-5 days), or the entire period (0-5 days). After 5 days of differentiation, these cells were subjected to Oil Red O staining for a quantitative (upper panel) and qualitative (lower panel) comparison of intracellular lipid accumulation. Data are the means \pm standard deviation (SD) values of at least 3 independent experiments. ${ }^{* *} \mathrm{P}<0.01 \mathrm{vs}$. D group. ND, no differentiation; D, differentiation; N, negative control (20 $\mu \mathrm{g} / \mathrm{ml}$ Radix astragali extract).
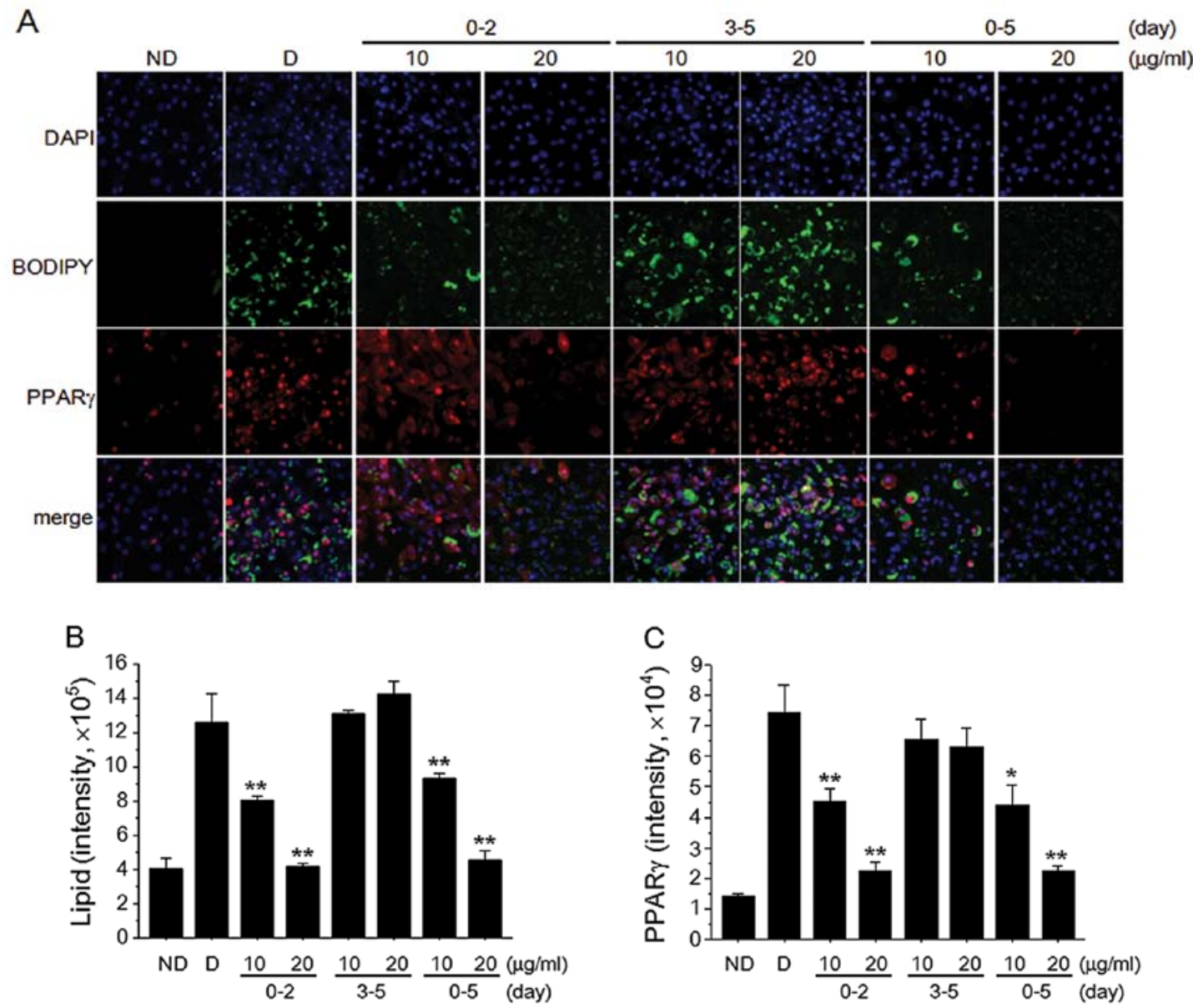

Figure 3. Effects of Pericarpium zanthoxyli extract (PZE) on lipid droplet formation and peroxisome proliferator-activated receptor $\gamma$ (PPAR $\gamma$ ) expression in OP9 cells. OP9 cells were stimulated with multiple daily insulin (MDI) to induce differentiation into adipocytes. Subsequently, $10 \mathrm{and} 20 \mu \mathrm{g} / \mathrm{ml}$ PZE were added at the early (0-2 days) and late stages of differentiation (3-5 days), or the entire period (0-5 days). (A) After 5 days of differentiation, immunohistochemical staining of the OP9 cells was carried out by using a specific antibody to visualize PPAR $\gamma$ (red) and BODIPY 493/503 for lipid droplets (green), and DAPI to visualize nuclei (blue). (B) Total cellular lipid droplet content was obtained by averaging BODIPY intensities from the cytosol of individual cells. (C) PPAR $\gamma$ concentrations were obtained by averaging intensities of antibody staining from the nuclei of individual cells. Approximately 5,000 cells were used for averaging intensities. Data are the means \pm standard deviation (SD) values of at least 3 independent experiments. ${ }^{~} \mathrm{P}<0.05$ vs. $\mathrm{D}$ group; ${ }^{* *} \mathrm{P}<0.01$ vs. $\mathrm{D}$ group. ND, no differentiation; D, differentiation. 

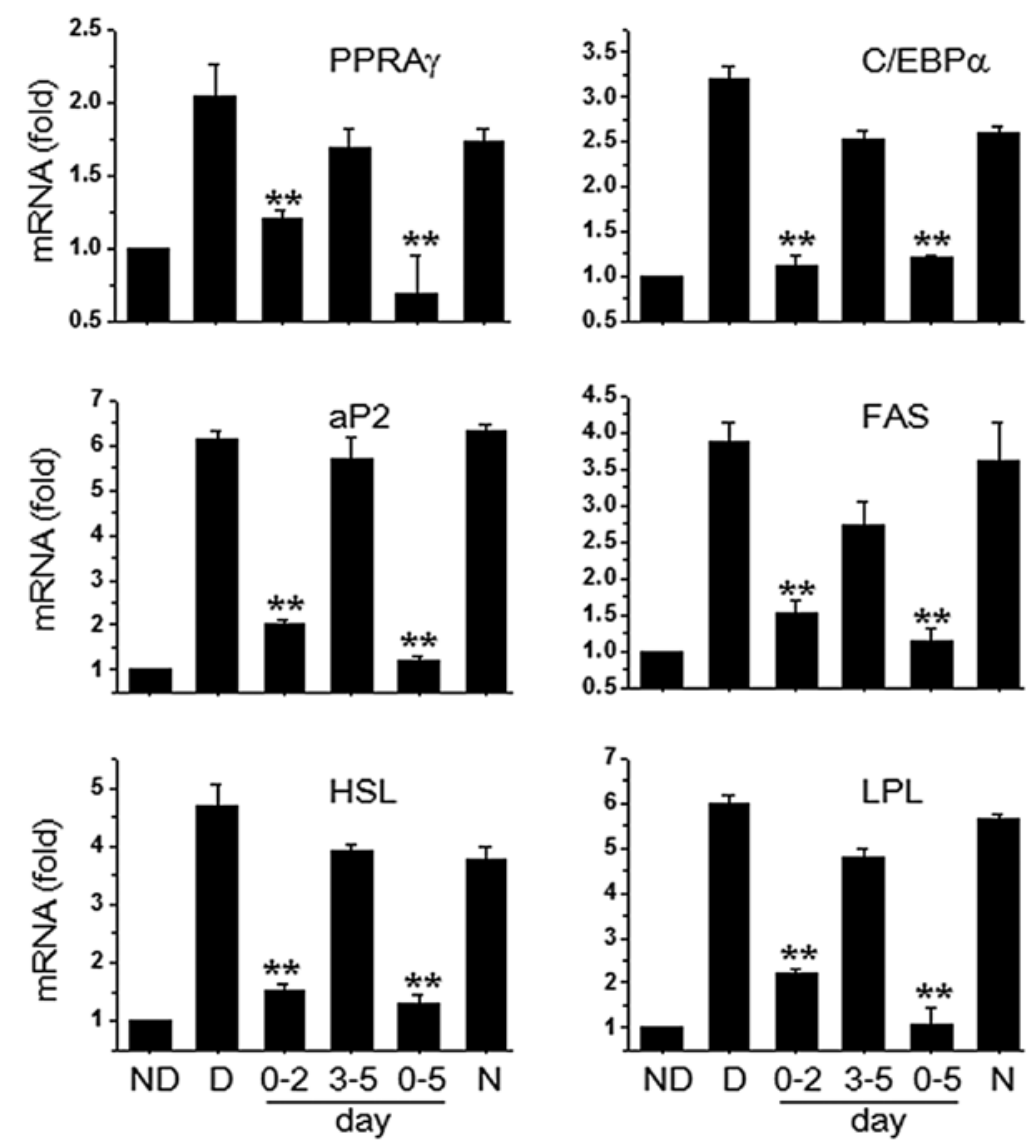

Figure 4. Effects of Pericarpium zanthoxyli extract (PZE) on the expression of peroxisome proliferator-activated receptor $\gamma$ (PPAR $\gamma$ ) and PPAR $\gamma$-targeted genes. OP9 cells were induced with MDI to induce differentiation into adipocytes. Subsequently, $20 \mu \mathrm{g} / \mathrm{ml} \mathrm{PZE} \mathrm{were} \mathrm{added} \mathrm{to} \mathrm{the} \mathrm{cells} \mathrm{at} \mathrm{the} \mathrm{early} \mathrm{(0-2} \mathrm{days)} \mathrm{and} \mathrm{late}$ stages of differentiation (3-5 days), or the entire period (0-5 days). After 5 days of differentiation, real-time PCR was carried out by using specific primers for PPAR $\gamma, \mathrm{CCAAT} /$ enhancer-binding protein $\alpha(\mathrm{C} / \mathrm{EBP} \alpha)$, adipocyte protein 2 (aP2), fatty acid synthase (FAS), hormone-sensitive lipase (HSL) and lipoprotein lipase (LPL). Data are the means \pm standard deviation (SD) values of at least 3 independent experiments. ${ }^{* *} \mathrm{P}<0.01$ vs. $\mathrm{D}$ group. ND, no differentiation; D, differentiation; N, negative control $(20 \mu \mathrm{g} / \mathrm{ml}$ Radix astragali extract).

we divided the adipogenesis process into an early (days 0-2) and late (days 3-5) stage. The formation of lipid droplets and the accumulation of triglycerides in the adipocytes treated with $20 \mu \mathrm{g} / \mathrm{ml}$ PZE were completely blocked during the early stage, as confirmed by Oil Red $\mathrm{O}$ staining in Fig. 2. We further investigated the inhibitory effects of PZE in adipocyte differentiation using the automated image acquisition and processing method. Early-stage treatment with PZE in the adipocyte differentiation process inhibited lipid droplet formation in a dose-dependent manner, as shown by BODIPY staining (green), which is a specific fluorescence dye for intracellular lipids (Fig. 3). In the same region, we examined PPAR $\gamma$ protein expression levels. PPAR $\gamma$ expression was downregulated follwoing early-stage treatment with PZE, but not after late-stage treatment. The effects of PZE on the formation of lipid droplets and PPAR $\gamma$ protein expression during the early stage were similar to those during the entire period of adipocyte differentiation (days 0-5). When the cells were treated with 10 or $20 \mu \mathrm{g} / \mathrm{ml}$ PZE during adipocyte differentiation, cytotoxicity was not demonstrated at the various time points compared to the control (untreated cells) cells (Fig. 1).

PZE decreases the expression of adipocyte differentiationrelated genes during early-stage treatment. Adipocyte differentiation is accompanied by the increased expression of various transcription factors and adipocyte-specific genes; PPAR $\gamma$ and $\mathrm{C} / \mathrm{EBP} \alpha$ are essential for terminal adipocyte differentiation (6,7). PPAR $\gamma$ and $\mathrm{C} / \mathrm{EBP} \alpha$ mRNA expression were markedly decreased following treatment with $20 \mu \mathrm{g}$ / $\mathrm{ml}$ PZE during the early stages, but not during the late stages (Fig. 4). We further investigated whether the PZE-induced reduction in PPAR $\gamma$ and $\mathrm{C} / \mathrm{EBP} \alpha$ levels regulated the expression of their target genes, including adipocyte protein 2 (aP2), fatty acid synthase (FAS), hormone-sensitive lipase (HSL) and lipoprotein lipase (LPL). Treatment with $20 \mu \mathrm{g} / \mathrm{ml}$ PZE during the early stages of differentiation and during the entire differentiation period markedly decreased the expression levels of aP2, FAS, HSL and LPL.

$P Z E$-inhibits the expression of $C / E B P \beta$ during the early stages of adipogenesis. $\mathrm{C} / \mathrm{EBP} \beta$ is a specific transcription factor expressed during the early stages of adipogenesis. $\mathrm{C} / \mathrm{EBP} \beta$ expression in OP9 adipocytes treated with 10 or $20 \mu \mathrm{g} / \mathrm{ml}$ PZE during the early stages markedly decreased in a dose-dependent manner (Fig. 5A and B). When growtharrested preadipocytes were treated with adipogenic inducers, the number of adipocytes increased by approximately 2-fold during the early stages. PZE markedly inhibited adipocyte proliferation during the early stages of differentiation, and the number of PZE-treated OP9 adipocytes was similar to 

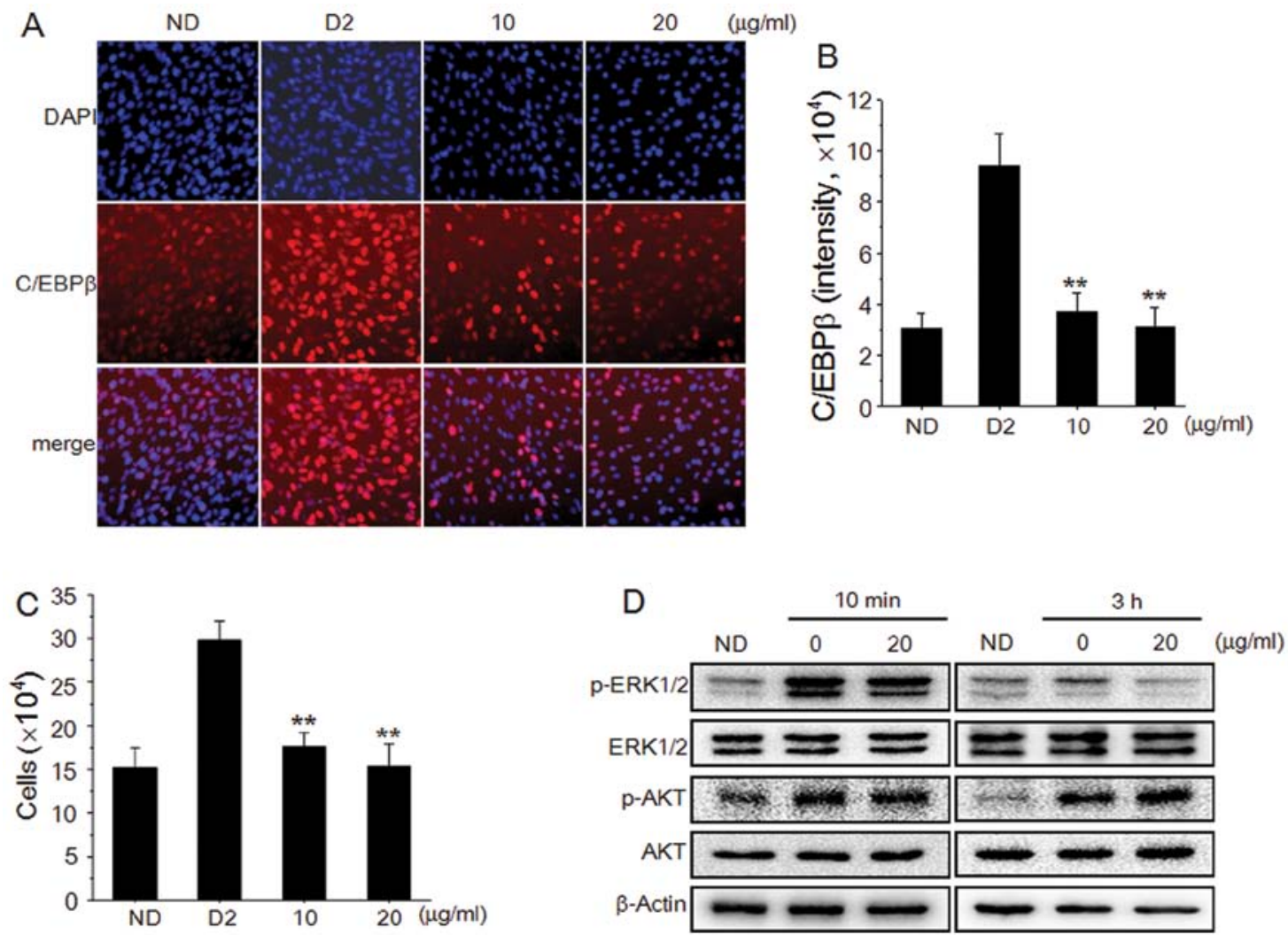

Figure 5. Effects of Pericarpium zanthoxyli extract (PZE) on CCAAT/enhancer-binding protein $\beta$ (C/EBP $\beta$ ) expression, cell proliferation and extracellular signal-regulated kinases 1/2 (ERK1/2) phosphorylation in OP9 cells. (A) OP9 cells were pre-treated with $10 \mathrm{or} 20 \mu \mathrm{g} / \mathrm{ml}$ PZE for $1 \mathrm{~h}$, and then cultured with multiple daily insulin (MDI) for 2 days. After 2 days of differentiation, immunohistochemical staining of OP9 cells was carried out by using a specific antibody to visualize $\mathrm{C} / \mathrm{EBP} \beta$ (red) and DAPI to visualize nuclei (blue). (B) $\mathrm{C} / \mathrm{EBP} \beta$ concentrations were obtained by averaging intensities of antibody staining from the nuclei of 5,000 individual cells. (C) The number of cells treated with 10 and $20 \mu \mathrm{g} / \mathrm{ml} \mathrm{PZE} \mathrm{was} \mathrm{determined} \mathrm{using} \mathrm{a} \mathrm{hemocytometer.} \mathrm{(D)} \mathrm{OP9} \mathrm{cells} \mathrm{treated}$ with $20 \mu \mathrm{g} / \mathrm{ml} \mathrm{PZE}$ for $10 \mathrm{~min}$ or $3 \mathrm{~h}$ were harvested, and the lysates were subjected to western blot analysis for ERK1/2, phospho-ERK1/2 (p-ERK1/2), protein kinase B (Akt), and phospho-Akt (p-Akt). Data are representative of triplicate experiments, and are the means \pm standard deviation (SD) values of at least 3 independent experiments. ${ }^{* *} \mathrm{P}<0.01$ vs. D2 group. ND, no differentiation; D2, differentiation day 2.

that of the control group (Fig. 5C). To determine the signaling pathway through which PZE inhibited clonal expansion during the early stages of adipogenesis, the expression of ERK and Akt was examined. Adipogenic inducers increased the phosphorylation of ERK1/2 and Akt. When the OP9 adipocytes were treated with $20 \mu \mathrm{g} / \mathrm{ml}$ PZE for $10 \mathrm{~min}$ or $3 \mathrm{~h}$, ERK1/2 phosphorylation was slightly decreased, but Akt phosphorylation was not decreased by treatment with PZE.

\section{Discussion}

In the present study, we investigated the anti-obesity effects of PZE in OP9 cells by measuring lipid accumulation, and by analyzing changes in adipocyte differentiation, which modulates adipocyte-specific gene expression. Preadipocytes can differentiate into adipocytes, which possess a spherical shape and accumulate lipid droplets $(5,6,10)$. In this study, treatment with PZE inhibited lipid accumulation and the differentiation of OP9 preadipocytes into adipocytes in a dose-dependent manner. Treatment with PZE also decreased the expression of key adipocyte differentiation regulators, including $\mathrm{C} / \mathrm{EBP} \beta$ and PPAR $\gamma$, and downregulated ERK phosphorylation.

At the molecular level, adipocyte differentiation is regulated by a complex transcriptional cascade that involves the sequential activation of C/EBPs and PPAR $\gamma(11) . \mathrm{C} / \mathrm{EBP} \beta$ and
$\mathrm{C} / \mathrm{EBP} \delta$ are rapidly and transiently expressed after hormonal induction of a differentiation cocktail, and $\mathrm{C} / \mathrm{EBP} \beta$ is required for MCE in the immediate early stages of adipocyte differentiation (12). These temporally expressed transcription factors are induced and activated by cAMP and glucocorticoids, and act synergistically to induce the expression of $\mathrm{C} / \mathrm{EBP} \alpha$ and PPAR $\gamma$, the master adipogenic transcription regulators (13). The expression of $\mathrm{C} / \mathrm{EBP} \alpha$ and PPAR $\gamma$ cross-regulate each other through a positive feedback loop and transactivate downstream target genes (aP2, LPL, FAS and HSL) that are adipocyte-specific and are involved in maintaining the adipocyte phenotype.

The OP9 adipocyte differentiation system was originally established by Wolins et al (8), and has often been used for adipocyte-related research (14-16). In our study, as shown in Figs. 2 and 3 confluent OP9 cells differentiated into adipocytes upon exposure to IBMX, DEXA and multiple daily insulin (MDI), which then activated a cascade of the adipogenic program. Treatment with PZE inhibited early-stage (days 0-2) adipocyte differentiation through the inhibition of $\mathrm{C} / \mathrm{EBP} \beta$ (Fig. 5A and B).

Adipogenesis is divided into the preadipocyte, early and late stages. OP9 cells undergo MCE through the upregulation of $\mathrm{C} / \mathrm{EBP} \beta$ during the early stages of adipocyte differentiation. This is followed by the activation of the downstream signaling transcription factors, PPAR $\gamma$ and $\mathrm{C} / \mathrm{EBP} \alpha(17)$. In this study, 
PZE inhibited the formation of lipid droplets and triglyceride accumulation, and suppressed $\mathrm{C} / \mathrm{EBP} \beta$ expression during the early stages of differentiation, as confirmed by Oil Red $\mathrm{O}$ staining (Fig. 2) and BODIPY staining (Fig. 3).

Clonal expansion occurs during the early stages of adipocyte differentiation, at which time the cell population is increased by 2 -fold (18). In this study, PZE inhibited adipocyte differentiation through the suppression of OP9 cell proliferation (Fig. 5C). Taken together, these results indicate that the major target of PZE for the inhibition of adipocyte differentiation in OP9 cells may be clonal expansion by targeting $\mathrm{C} /$ EBP $\beta$ expression during the early stages of differentiation.

The ERK pathway is necessary for the initiation of the early stages of adipogenesis, and acts as a mitogenic signaling molecule in adipocyte differentiation (19,20). Adipogenic inducers stimulate the MAPK/ERK pathway, which is followed by the enhanced activity of $\mathrm{C} / \mathrm{EBP} \beta$ and the induction of adipocyte differentiation $(20,21)$. The activation of the Akt pathway in 3T3-L1 preadipocytes can also induce adipogenesis $(4,22,23)$. In this study, adipogenic inducers stimulated the phosphorylation of ERK1/2 and Akt following treatment with PZE for 10 min and $3 \mathrm{~h}$, but ERK1/2 phosphorylation was only decreased by treatment with PZE for $3 \mathrm{~h}$ (Fig. 5D). Akt phosphorylation and cyclin D1 (data not shown) expression were not affected by treatment with PZE. Muise-Helmericks et al (24) reported that the PI3K/Akt pathway affects cell cycle progression through the regulation of cyclin D and p27 expression (Fig. 5D). This suggests that the inhibition of $\mathrm{C} / \mathrm{EBP} \beta$ expression by $\mathrm{PZE}$ is the result of the decrease in ERK phosphorylation, not Akt phosphorylation.

In conclusion, this study indicates a new role for PZE in adipocyte differentiation through targeting the early cellular events of adipogenesis, such as MCE and the expression of early adipogenic transcription factors. These results identify a possible mechanism of action of PZE, suggesting that the PZE-induced inhibition of ERK phosphorylation suppresses adipogenesis by inhibiting other signaling cascades that include $\mathrm{C} / \mathrm{EBPs}$ and PPAR $\gamma$ during the process of OP9 adipocyte differentiation. Taken together, our findings provide important insight into the mechanisms underlying the anti-obesity activity of PZE.

\section{Acknowledgements}

This study was supported by a National Research Foundation of Korea (NRF) grant, funded by the Korean Government (MEST) (no. 2011-0030130), Republic of Korea, and by a Basic Science Research Program grant from the National Research Foundation of Korea (NRF), funded by the Ministry of Education, Science, and Technology (NRF-2012R1A1A4A0 1011520).

\section{References}

1. Schuster DP: Obesity and the development of type 2 diabetes: the effects of fatty tissue inflammation. Diabetes Metab Syndr Obes 3: 253-262, 2010.

2. Caro JF, Dohm LG, Pories WJ and Sinha MK: Cellular alterations in liver, skeletal muscle, and adipose tissue responsible for insulin resistance in obesity and type II diabetes. Diabetes Metab Rev 5: 665-689, 1989.
3. Martin RJ, Ramsay T and Hausman GJ: Adipocyte development. Pediatr Ann 13: 448-453, 1984.

4. Gregoire FM, Smas CM and Sul HS: Understanding adipocyte differentiation. Physiol Rev 78: 783-809, 1998.

5. Tong Q and Hotamisligil GS: Molecular mechanisms of adipocyte differentiation. Rev Endocr Metab Disord 2: 349-355, 2001.

6. Ntambi JM and Young-Cheul K: Adipocyte differentiation and gene expression. J Nutr 130: 3122S-3126S, 2000.

7. Student AK, Hsu RY and Lane MD: Induction of fatty acid synthetase synthesis in differentiating 3T3-L1 preadipocytes. J Biol Chem 255: 4745-4750, 1980.

8. Wolins NE, Quaynor BK, Skinner JR, et al: OP9 mouse stromal cells rapidly differentiate into adipocytes: characterization of a useful new model of adipogenesis. J Lipid Res 47: 450-460, 2006.

9. Bradford MM: A rapid and sensitive method for the quantitation of microgram quantities of protein utilizing the principle of protein-dye binding. Anal Biochem 72: 248-254, 1976.

10. Otto TC and Lane MD: Adipose development: from stem cell to adipocyte. Crit Rev Biochem Mol Biol 40: 229-242, 2005.

11. Alessi MC, Lijnen HR, Bastelica D and Juhan-Vague I: Adipose tissue and atherothrombosis. Pathophysiol Haemost Thromb 33: 290-297, 2003.

12. Tang QQ, Otto TC and Lane MD: CCAAT/enhancer-binding protein beta is required for mitotic clonal expansion during adipogenesis. Proc Natl Acad Sci USA 100: 850-855, 2003.

13. Farmer SR: Transcriptional control of adipocyte formation. Cell Metab 4: 263-273, 2006.

14. Kotake D and Hirasawa N: Activation of a retinoic acid receptor pathway by thiazolidinediones induces production of vascular endothelial growth factor/vascular permeability factor in OP9 adipocytes. Eur J Pharmacol 707: 95-103, 2013.

15. Saitoh Y, Mizuno H, Xiao L, Hyoudou S, Kokubo K and Miwa N: Polyhydroxylated fullerene $\mathrm{C}_{60}(\mathrm{OH})_{44}$ suppresses intracellular lipid accumulation together with repression of intracellular superoxide anion radicals and subsequent PPAR $\gamma 2$ expression during spontaneous differentiation of OP9 preadipocytes into adipocytes. Mol Cell Biochem 366: 191-200, 2012.

16. Saitoh Y, Xiao L, Mizuno H, et al: Novel polyhydroxylated fullerene suppresses intracellular oxidative stress together with repression of intracellular lipid accumulation during the differentiation of OP9 preadipocytes into adipocytes. Free Radic Res 44: 1072-1081, 2010.

17. Park BO, Ahrends R and Teruel MN: Consecutive positive feedback loops create a bistable switch that controls preadipocyte-to-adipocyte conversion. Cell Rep 2: 976-990, 2012.

18. Bernlohr DA, Bolanowski MA, Kelly TJ Jr and Lane MD: Evidence for an increase in transcription of specific mRNAs during differentiation of 3T3-L1 preadipocytes. J Biol Chem 260: 5563-5567, 1985.

19. Roberts EC, Shapiro PS, Nahreini TS, Pages G, Pouyssegur J and Ahn NG: Distinct cell cycle timing requirements for extracellular signal-regulated kinase and phosphoinositide 3-kinase signaling pathways in somatic cell mitosis. Mol Cell Biol 22: 7226-7241, 2002.

20. Tang QQ, Otto TC and Lane MD: Mitotic clonal expansion: a synchronous process required for adipogenesis. Proc Natl Acad Sci USA 100: 44-49, 2003.

21. Prusty D, Park BH, Davis KE and Farmer SR: Activation of MEK/ERK signaling promotes adipogenesis by enhancing peroxisome proliferator-activated receptor gamma (PPARgamma) and C/EBPalpha gene expression during the differentiation of 3T3-L1 preadipocytes. J Biol Chem 277: 46226-46232, 2002.

22. Kohn AD, Summers SA, Birnbaum MJ and Roth RA: Expression of a constitutively active Akt Ser/Thr kinase in 3T3-L1 adipocytes stimulates glucose uptake and glucose transporter 4 translocation. J Biol Chem 271: 31372-31378, 1996.

23. Magun R, Burgering BM, Coffer PJ, et al: Expression of a constitutively activated form of protein kinase B (c-Akt) in 3T3-L1 preadipose cells causes spontaneous differentiation. Endocrinology 137: 3590-3593, 1996.

24. Muise-Helmericks RC, Grimes HL, Bellacosa A, Malstrom SE, Tsichlis PN and Rosen N: Cyclin D expression is controlled post-transcriptionally via a phosphatidylinositol 3-kinase/ Akt-dependent pathway. J Biol Chem 273: 29864-29872, 1998. 